\title{
Habitat Use by the Eastern Sand Darter, Ammocrypta pellucida, in Two Lake Champlain Tributaries
}

\author{
Shannon M. O'Brien and Douglas E. FaceY ${ }^{1}$ \\ Department of Biology, Saint Michael's College, Colchester, Vermont 05439 USA \\ ${ }^{1}$ Corresponding Author's Current Address: Department of Biology, Box 283, One Winooski Park, Saint Michael's College, \\ Colchester, Vermont 05439 USA
}

O'Brien, Shannon M., and Douglas E. Facey. 2008. Habitat use by the Eastern Sand Darter, Ammocrypta pellucida, in two Lake Champlain tributaries. Canadian Field-Naturalist 122(3): 239-246.

The Eastern Sand Darter (Ammocrypta pellucida) is endangered or threatened throughout much of its range, which includes the St. Lawrence-Lake Ontario drainage of southern Ontario and Quebec and several Vermont tributaries of Lake Champlain. The species is known for its tendency to burrow, and field observations have suggested that habitat use may depend on substrate particle size. To determine whether Eastern Sand Darter densities were correlated with substrate particle size, fish and substrates were sampled in 156 plots in two Vermont rivers during the summers of 2001 and 2002. The Eastern Sand Darter occurred mainly in areas in which substrate composition was over $45 \%$ fine to medium sand $(0.24-0.54 \mathrm{~mm})$; they were much less abundant in areas in which substrate composition exceeded $25 \%$ particles greater than $1.9 \mathrm{~mm}$. Substrate preference was tested by allowing 49 fish kept in aquaria to choose among four different substrates. The fish showed a significant preference $(P<0.005)$ for the finer substrate categories $(0.24-0.54 \mathrm{~mm}, 0.55-1.0 \mathrm{~mm})$, and mostly avoided the coarser substrates (1.0-1.9 mm, 2.0-4.1 mm). This suggests that the Eastern Sand Darter is selective regarding substrate composition, and therefore might be affected by fluctuations or changes in substrate composition within its habitat, such as those caused by changes in flow.

Key Words: Eastern Sand Darter, Ammocrypta pellucida, habitat, substrate choice, Poultney River, Winooski River, New York, Vermont.

The range of the Eastern Sand Darter (Ammocrypta pellucida, Percidae) extends from the St. Lawrence River and the Lake Champlain drainage to southwestern Ontario, southeastern Michigan, and throughout much of the Ohio River basin to West Virginia and Kentucky (Page 1983; Smith 1985). The Eastern Sand Darter is generally rare throughout its range, and is usually found in streams and rivers with sand substrate, but not in areas with silt or mud (Smith 1985). Daniels (1993) observed that sand darters in the Mettawee River, New York, were found only in areas where substrates were at least $90 \%$ sand, and $90 \%$ of all sand darters in an artificial stream selected sand (0.25-0.5 $\mathrm{mm}$ particle size) over gravel $(1-2 \mathrm{~cm})$ or rubble $(8-$ $15 \mathrm{~cm}$ ).

The Eastern Sand Darter burrows in sandy substrates, which may help the fish hold position and conserve energy in unstable sandy habitats (Daniels 1989). The burrowing behavior makes the species sensitive to siltation, which can decrease oxygen availability and may affect prey availability. Drake et al. (2008) found that growth rates of age-0 Eastern Sand Darter were higher in sand-dominated substrates than in silt-dominated substrates. This sensitivity to clean, sandy substrates makes the Eastern Sand Darter a good indicator of habitat quality.

Historical information suggests that the Eastern Sand Darter was common in tributaries of both the Ohio and St. Lawrence rivers (Page 1983), but its distribution and abundance have decreased throughout much of its range, perhaps due to habitat degradation (Trautman 1957, 1981). Agricultural and industrial pollution, channelization, the creation of impoundments, and land use practices such as removal of riparian vegetation and urban/suburban development which increase erosion and runoff all potentially alter the substrate composition within rivers (Clay 1975; Smith 1979). As a result, formerly sandy areas that had supported sand darters may no longer be suitable, resulting in declines in local populations (Scott and Crossman 1973; Smith 1985; Daniels 1993; Holm and Mandrak 1996; Grandmaison et al. 2004*; Drake et. al 2008).

The declines in Eastern Sand Darter populations associated with increased sedimentation and other human impacts have resulted in the species being classified as globally rare (G3) and receiving protected designations in the Canadian provinces of Ontario and Quebec (COSEWIC 2008*; Drake et al. 2008), and several U.S. states including Vermont, New York, and Michigan (Grandmaison et. al 2004*). However, the development of management or recovery plans has been hampered by the lack of fundamental biological information such as life history characteristics and habitat requirements. Field observations suggest that the Eastern Sand Darter does not use all sandy habitats equally, and that it is more likely to be found in shallow areas with low current velocity and soft, fine to medium sand (Facey 1998). The objective of this study was to characterize the sediment particle sizes preferred by the Eastern Sand Darter more precisely than 
Daniels (1993) in order to provide information pertinent to long-term habitat management for the benefit of the species.

\section{Materials and Methods}

The study utilized two different Lake Champlain tributaries. The Poultney River forms part of the border between New York and Vermont and flows into the south end of Lake Champlain, and the Winooski River drains a large portion of central Vermont and empties into Lake Champlain north of the city of Burlington.

Between 30 July and 7 August 2001, we sampled substrate and fish from 99 plots within a $1.6-\mathrm{km}$ stretch of a meandering section of the Poultney River upstream from the mouth of the Hubbardton River $\left(43^{\circ} 37^{\prime} 35.93^{\prime \prime N}, 73^{\circ} 20^{\prime} 34.35^{\prime \prime} \mathrm{W}\right)$. The sampled section was generally $10-20 \mathrm{~m}$ wide, shallow, sandy, and meandering with steep, sandy banks. Between 3 June and 25 July 2002 we sampled substrate and fish in 57 plots within a $10-\mathrm{km}$ stretch of the Winooski River downstream from the city of Winooski, Vermont $\left(44^{\circ} 29^{\prime} 18.64^{\prime \prime} \mathrm{N}, 73^{\circ} 11^{\prime} 21.27^{\prime \prime} \mathrm{W}\right)$. This stretch of the river is mostly $30-50 \mathrm{~m}$ wide with a deep channel, but there were shallow areas near islands and along the depositional bank in meandering sections.

In both river sections we sampled all available areas less than $0.5 \mathrm{~m}$ in depth and with surface velocities less than about $0.5 \mathrm{~m} / \mathrm{sec}$. Deeper or faster areas were not sampled because these conditions make it too difficult to keep the seine on the substrate, which is necessary to capture sand darters. Most sample plots were $3 \mathrm{~m} \times 10 \mathrm{~m}$, but in some cases plot size varied slightly due to water depth or the presence of obstructions in the river. In all cases, substrate composition appeared quite homogeneous within each plot. A single substrate sample from each plot was collected in a $200-\mathrm{ml}$ container from the top $4-6 \mathrm{~cm}$ of the substrate of an area representative of the substrate surface composition of the entire plot. Each plot was seined once, always moving upstream, with either a $4.76 \mathrm{~mm}$ mesh straight seine (32 plots in the Poultney River) or a bag seine with $6.35 \mathrm{~mm}$ mesh wings and $4.76 \mathrm{~mm}$ mesh collecting bag (all other plots). The number of individuals of each fish species caught was recorded, and the standard length $(\mathrm{mm})$ of all sand darters was measured.

A chi-square analysis was employed to determine if there was evidence of non-random habitat selection. We assumed that if the Eastern Sand Darter randomly selected habitats, then the distribution of plots with a certain number of fish would resemble a Poisson distribution. In addition, any trends between substrate composition and the number of sand darters captured were noted. Each of the substrate samples was dried and separated into different substrate size components by sifting through a series of sieves. The sieve screen sizes were \#5 (4.1 mm), \#10 (1.9 mm), \#18 (1.0 mm), \#35 $(0.54 \mathrm{~mm}), \# 60(0.23 \mathrm{~mm})$, and \#120 (0.12 mm). Once separated, each size component was weighed and the percent composition by weight was calculated. Plots were grouped based on sand darter densities, and average percent composition for each particle size was determined for all the plots that had the same density of sand darters.

From late August through early October 2002, we observed substrate choice by 49 Eastern Sand Darter kept in $37.9 \mathrm{~L}$ aquaria. Each week seven to 10 fish were collected from the Winooski River, returned to the lab, and maintained in three aquaria. The bottom of each aquarium was divided into four equal quadrants using 2-cm high plastic dividers, and each quadrant received a 2-cm layer of substrate, either $0.23-0.54 \mathrm{~mm}, 0.55-$ $1.0 \mathrm{~mm}, 1.1-1.9 \mathrm{~mm}$, or $2.0-4.1 \mathrm{~mm}$ in size. Finer sediments were not used because the particles would not remain settled due to fish activity and a slight current created by the filter. To reduce the potential impact of stimuli outside the tank affecting the substrate choice by fish within each tank, the arrangement of the quadrants with different sizes of substrate was different in the three tanks. During daylight hours, all fish in each tank were observed approximately every 2 hours and the substrate size of the fish's location and whether or not it was burrowed were recorded. If the fish was not visible, we assumed it had burrowed and we used a plastic pipette to gently agitate the substrate until the fish emerged. We observed the fish daily for one week, and then returned them to the river. To determine whether the Eastern Sand Darter showed a preference for substrate consisting of certain sized particles, we performed a chi-square analysis using fish locations in one randomly chosen observation period for each group of fish, thereby preventing the use of multiple observations of a single individual.

\section{Results}

A total of 42 adult Eastern Sand Darters (48-57 mm SL) was captured from the Poultney River plots. Eighty plots had no sand darters, nine plots contained one, six plots had two, two plots contained four, one plot contained six, and one plot had seven sand darters. The 42 sand darters caught in the 99 different plots did not follow a Poisson distribution (chi-square $=17.85$, $P=0.00002,1 \mathrm{df})$. To perform the chi-square analysis and maintain an expected value above five for each category, we grouped plots into three categories by number of sand darters: plots with zero, one, or two or more (Table 1; see also Facey and O'Brien 2004).

In general, Eastern Sand Darter density was highest in plots with lower percentages of substrate greater than $1.9 \mathrm{~mm}$ in size (Figure 1). For example, half of the plots with no sand darters had 5 to $40 \%$ composition by weight of substrate sized greater than $4.1 \mathrm{~mm}$, with the median and mean approximately the same, at just over $20 \%$. In comparison, all plots with two or more sand darters had under $20 \%$ composition by weight of substrate greater than $4.1 \mathrm{~mm}$, with the median and 
80 Plots with 0 Eastern Sand Darter

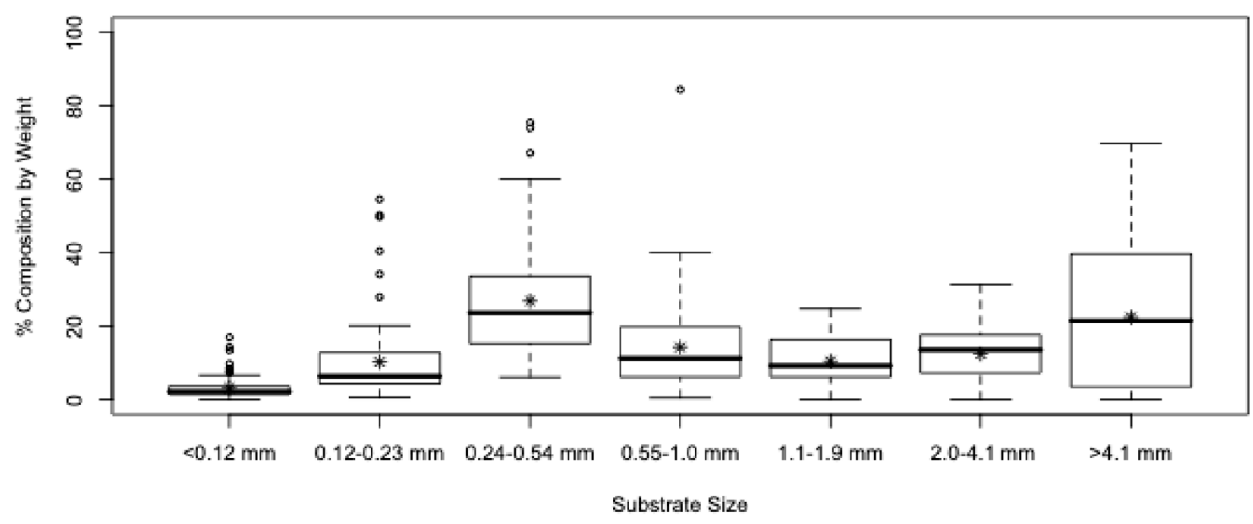

9 Plots with 1 Eastern Sand Darter

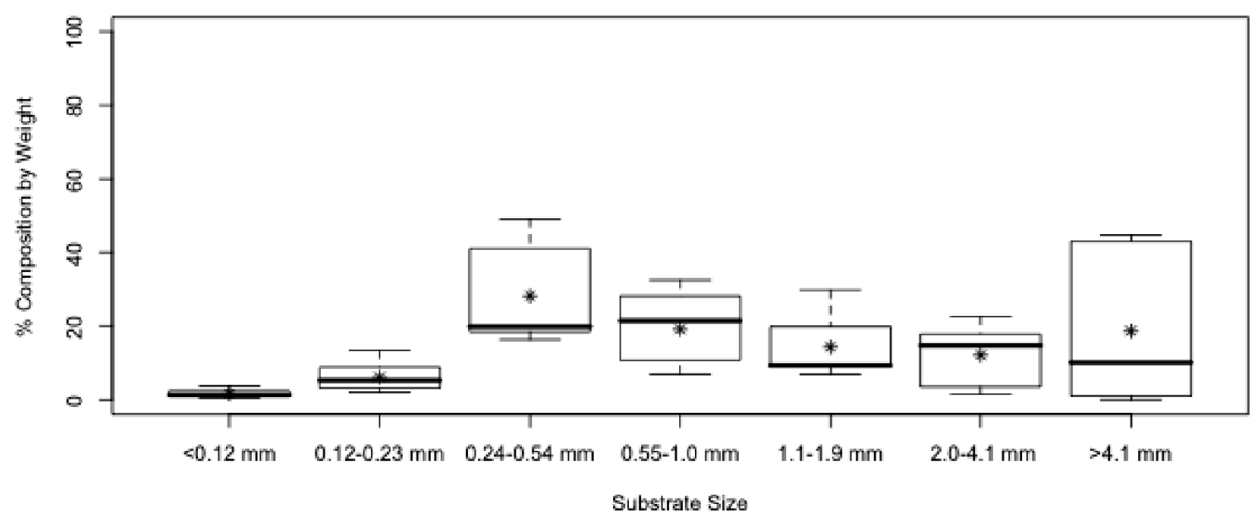

10 Plots with 2 or more Eastern Sand Darter

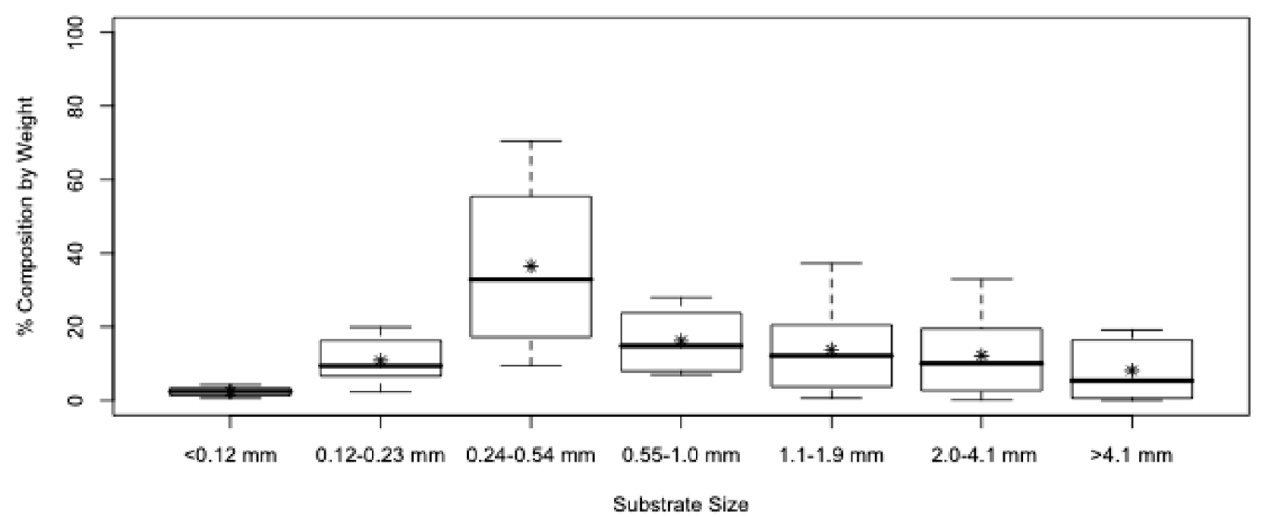

FIGURE 1. The percent composition of substrate by weight for plots with different densities of the Eastern Sand Darter (number per $30 \mathrm{~m}^{2}$ ) in the Poultney River (2001). The box represents the interquartile range (IQR, 50\% of the data surrounding the median), vertical dashed lines represent the range of data that falls between $\mathrm{Q} 1-1.5^{*} \mathrm{IQR}$ and Q3+ $1.5^{*} \mathrm{IQR}$, asterisk shows mean, black bar shows median, and circles represents outliers (those values that are greater than $\mathrm{Q} 3+1.5 * \mathrm{IQR})$. 
mean at approximately $7 \%$. Plots with no sand darters also had a much larger range for percent composition of substrate greater than $4.1 \mathrm{~mm}$, with a minimum of $0 \%$ and a maximum of $70 \%$, unlike the plots with two or more sand darters which showed a maximum under $20 \%$. Plots with no sand darters also had less variation in percent composition of substrate $2.0-4.1 \mathrm{~mm}$ in size; half of these plots contained between 8 and $18 \%$ composition by weight of this size substrate. Plots with two or more sand darters had greater variability of percent composition of substrate $2.0-4.1 \mathrm{~mm}$, but more plots contained below $10 \%$ composition by weight. Plots with one sand darter had less variability and smaller percent compositions of substrate sized greater than $1.9 \mathrm{~mm}$ than plots with no sand darters, but still had higher mean and median values than plots with two or more sand darters.

The other main difference between plots with no sand darters and those with two or more was percent composition of substrate sized $0.12-0.23 \mathrm{~mm}$ and $0.24-0.54 \mathrm{~mm}$. Areas with a higher density of sand darters usually had a large percentage of fine to medium sized sand (0.12-0.23 $\mathrm{mm}$ and $0.24-0.54 \mathrm{~mm})$. Half of the plots with no sand darters had between 15 and $30 \%$ of substrate $0.24-0.54 \mathrm{~mm}$ in size, with a mean and median below $30 \%$. In contrast, half of the plots with two or more sand darters had 15 to $60 \%$ substrate sized $0.24-0.54 \mathrm{~mm}$, with a mean and median above $30 \%$. Similarly, more of the plots with two or more sand darters had over $10 \%$ composition of $0.12-0.23$ $\mathrm{mm}$ substrate than did plots with none or one sand darter.

The 2002 sampling of the Winooski River yielded 112 adult Eastern Sand Darter (32-54 mm SL) from 12 of the 57 plots sampled. Forty-five plots had no sand darters, four plots contained one, three plots contained two, and each of the following densities was found in one plot: three, six, seven, 11 , and 74 sand darters. Chi-square analysis showed that the sand darters did not follow a Poisson distribution throughout the sampled plots of the Winooski River (chi-square $=206.3$, $P<0.000001,3 \mathrm{df})$. For this chi-square analysis, we grouped the plots into five different categories based on the number of sand darters $(0,1,2,3,4$ or more) to ensure that the expected value for each category was above five (Table 2).

The Eastern Sand Darter in the Winooski River showed trends similar to those observed in the Poultney River. Plots with 2 or more sand darters averaged a small percentage of particles greater than $1.9 \mathrm{~mm}$, with half of the plots having less than $10 \%$ composition of substrate greater than $1.9 \mathrm{~mm}$. In contrast, plots with none or one sand darter averaged a large percentage of substrate greater than $4.1 \mathrm{~mm}$. Plots with no sand darters had a median value of almost $50 \%$ composition of substrate greater than $4.1 \mathrm{~mm}$ and a mean value of $35 \%$ (Figure 2). There also seems to be a correlation between density of sand darters and percent composi-
TABLE 1. The number of plots expected and observed in the Poultney River with different densities of Eastern Sand Darter (number of fish per $30 \mathrm{~m}^{2}$ ). Expected values are based on the Poisson distribution, which predicts how many of the 99 plots sampled would contain the indicated number of fish if habitat selection was random.

\begin{tabular}{ccc}
\hline \hline $\begin{array}{c}\text { Number } \\
\text { of Fish }\end{array}$ & $\begin{array}{c}\text { Expected number } \\
\text { of plots }\end{array}$ & $\begin{array}{c}\text { Observed number } \\
\text { of plots }\end{array}$ \\
\hline 0 & 64.5 & 80 \\
1 & 27.7 & 9 \\
$\geq 2$ & 6.8 & 10 \\
\hline \hline
\end{tabular}

TABLE 2. The number of plots expected and observed in the Winooski River with different densities of Eastern Sand Darter (number of fish per $30 \mathrm{~m}^{2}$ ). Expected values are based on the Poisson distribution, which predicts how many of the 57 plots sampled would contain the indicated number of fish if habitat selection was random.

\begin{tabular}{ccc}
\hline \hline $\begin{array}{c}\text { Number } \\
\text { of Fish }\end{array}$ & $\begin{array}{c}\text { Expected number } \\
\text { of plots }\end{array}$ & $\begin{array}{c}\text { Observed number } \\
\text { of plots }\end{array}$ \\
\hline 0 & 7.8 & 45 \\
1 & 15.6 & 4 \\
2 & 15.5 & 3 \\
3 & 10.2 & 1 \\
$\geq 4$ & 7.9 & 4 \\
\hline \hline
\end{tabular}

tion of fine and medium sand $(0.24-1.0 \mathrm{~mm})$. Figure 2 shows that plots with two or more sand darters had substrate that averaged 12 to $65 \% \quad 0.24-0.54 \mathrm{~mm}$, with median and mean between 30 and $40 \%$. In comparison, plots with no sand darters had more variability of composition of $0.24-0.54 \mathrm{~mm}$ and a much lower median value. Although plots with one sand darter did have median and mean values for substrate sized 0.24-1.0 mm, somewhat similar to plots with two or more sand darters, the plots with one sand darter averaged less substrate that was $0.24-0.54 \mathrm{~mm}$ and also contained much larger amounts of the coarsest sized substrate $(>4.1 \mathrm{~mm})$.

Overall, the Eastern Sand Darter in both rivers occurred in areas that contained a considerable percentage of substrate particles in the $0.24-0.54 \mathrm{~mm}$ and $0.55-1.0 \mathrm{~mm}$ categories (Figures 1,2). Our results show that for the majority of plots with sand darters, the largest percentage of substrate was $0.24-1.0 \mathrm{~mm}$ and the smallest percentage was usually $2.0 \mathrm{~mm}$ or greater. However, there were some exceptions to these trends noticed in both the Poultney and Winooski rivers. For example, in the Poultney River one plot with seven sand darters had substrate compositions more similar to plots with only one or two sand darters; however, this was only a single plot and although over $30 \%$ of the substrate was larger than $1.9 \mathrm{~mm}$, the majority of the substrate in the sample was between 0.12 and $1.0 \mathrm{~mm}$.

Although the field studies showed associations between substrate composition and fish distribution, they 


\section{Plots with 0 Eastern Sand Darter}

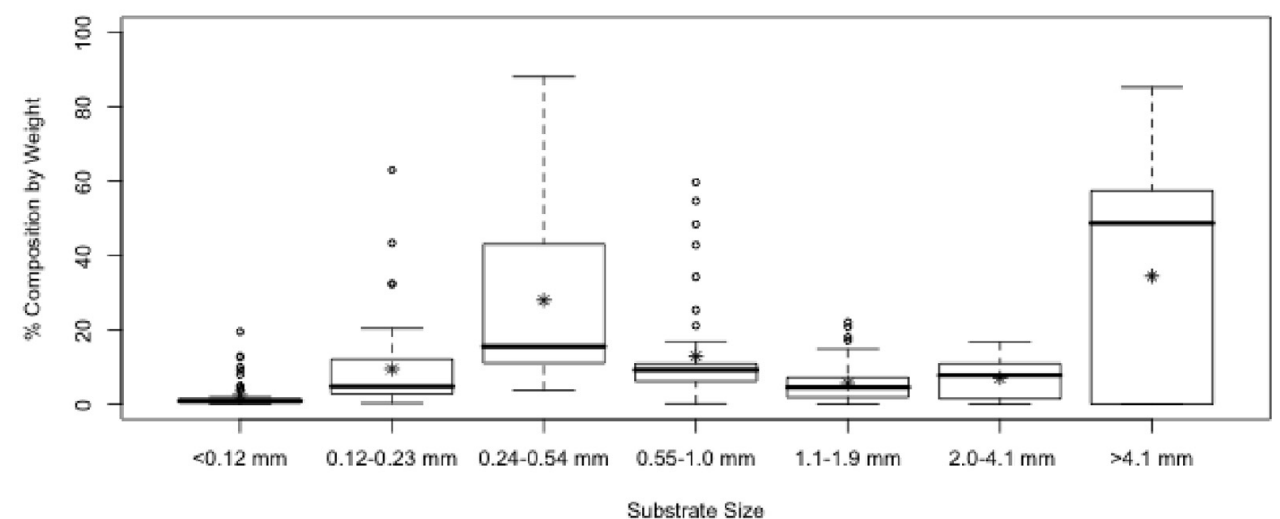

4 Plots with 1 Eastern Sand Darter

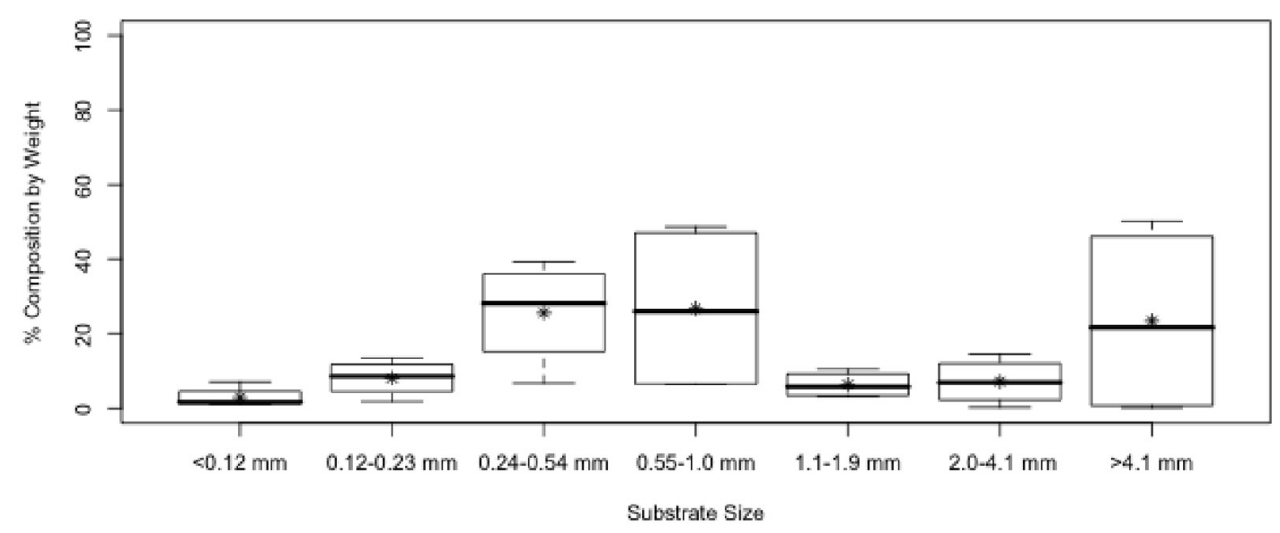

8 Plots with 2 or more Eastern Sand Darter

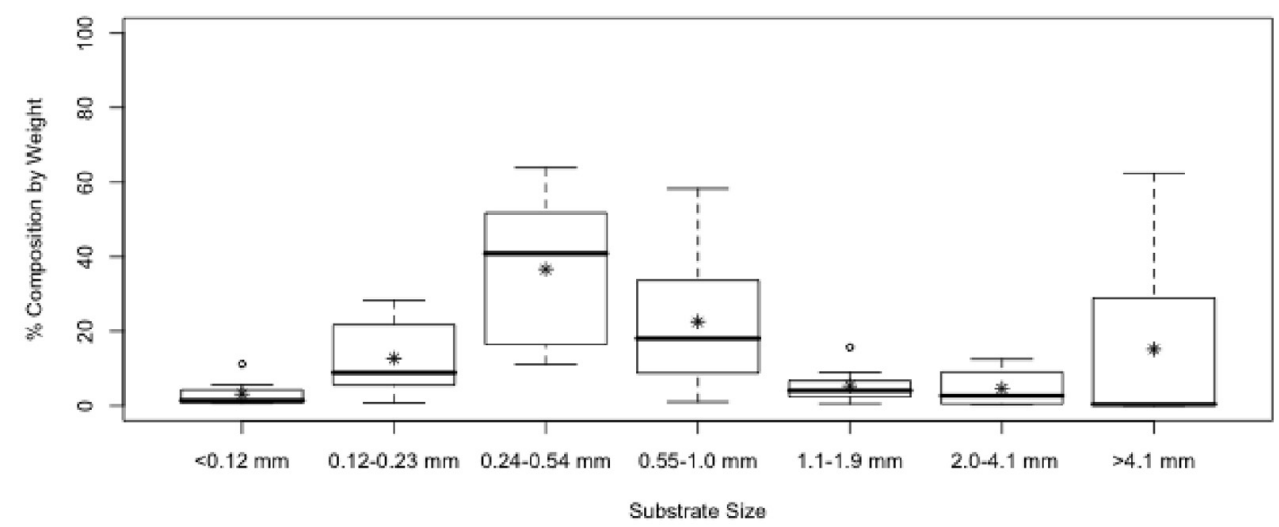

FIGURE 2. The percent composition of substrate by weight for plots with different densities of the Eastern Sand Darter (number per $30 \mathrm{~m}^{2}$ ) in the Winooski River (2002). The box represents the interquartile range (IQR, 50\% of the data surrounding the median), vertical dashed lines represent the range of data that falls between Q1 $-1.5 * \mathrm{IQR}$ and Q3 $+1.5 * \mathrm{IQR}$, asterisk shows mean, black bar shows median, and circles represents outliers (those values that are greater than Q3 $+1.5 * \mathrm{IQR})$. 
did not allow us to determine whether the Eastern Sand Darter showed a substrate preference. The laboratory study did, however, and the results suggest that sand darters preferred burrowing into the substrate rather than being on the substrate, and that they preferred substrate particles less than $1.1 \mathrm{~mm}$ in size. From a total of 912 observations made of 49 different fish, $790(87 \%)$ were of burrowed fish and only $122(13 \%)$ were of fish on the substrate. Overall, as the particle size of the substrate decreased, the tendency of the sand darters to burrow in it increased, and the fish were most often burrowed in the smallest substrate particle size available in the tank (Figure 3). Fish that were not burrowed showed a similar trend in frequency of observation on the different substrates. Throughout the study we also observed failed attempts by some of the fish to burrow into the $2.0-4.1 \mathrm{~mm}$ sized substrate; they then moved to another size substrate. A Chi-square analysis of the randomly selected observation periods of the Eastern Sand Darter held in aquaria showed that substrate selection was not random (Chi-square $=28.9$, $P<0.005 ; \mathrm{df}=3$ ), and suggests a strong preference for the two smallest substrate particle sizes (Table 3).

\section{Discussion}

The Eastern Sand Darter in both the Poultney and Winooski rivers inhabited areas with similar substrate characteristics; most were found in areas with a high percentage of fine- and medium-sized sand (particles 0.12 to $1.0 \mathrm{~mm}$ ) and low percentages of substrate particles over $1.9 \mathrm{~mm}$. In addition, aquarium studies showed that the Eastern Sand Darter preferred fineto medium- sized sand when given a choice of substrates, which was consistent with the trends that we observed between substrate composition and the distribution of sand darters in the rivers.

Previous studies have indicated that the preferred habitat of the Eastern Sand Darter is areas with fine sandy substrate and shallow, slow-flowing water (Daniels 1993; Facey 1998). Many of the locations in which we found the Eastern Sand Darter fit this description. In the Winooski River, we collected 74 sand darters in one plot in a sandy area along the downstream side of an island with no measurable water velocity. The collection of so many sand darters in one plot may have been due to our sampling a drop-off along the edge of the sandbar, which allowed us to dig into the edge of the sand bar with the seine. This is not the first time that we have noticed greater success when we are able to penetrate into the sand with the seine, rather than skimming across the surface.

The only other study that we know of that has tested Eastern Sand Darter substrate choice in an artificial setting is that of Daniels (1993), who ran four trials using a $4 \mathrm{~m} \times 0.6 \mathrm{~m}$ tank with three substrate sections of equal area. Each section contained a different sediment particle size: sand $(0.25-0.5 \mathrm{~mm})$, gravel $(1-2 \mathrm{~cm})$, or rubble $(8-15 \mathrm{~cm})$. Daniels (1993) varied
TABLE 3. The number of Eastern Sand Darters observed burrowed in each of the four different sized substrates that were available in each aquarium. If the fish showed no preference, we would expect approximately equal representation among the four sediment categories. A chi-square analysis showed a highly significant preference for the smaller sediment categories $(P<0.005)$.

\begin{tabular}{cc}
\hline \hline Sediment size $(\mathrm{mm})$ & Number Observed \\
\hline $0.24-0.54$ & 23 \\
$0.55-1.0$ & 16 \\
$1.1-1.9$ & 4 \\
$2.0-4.1$ & 1 \\
\hline \hline
\end{tabular}

the depth and velocity of the water in the holding tank to simulate natural river conditions for different times of year, and reported that $84 \%$ to $90 \%$ of fish were found on the sandy substrate under all depth and velocity conditions. Less than $3 \%$ of the observations were of fish on the rubble. Our aquarium study was conducted to determine a finer resolution of substrate preference; therefore, we tested substrates in finer categories and found that $89 \%$ of the fish tested chose substrate between 0.24 and $1.0 \mathrm{~mm}$.

Welsh and Perry (1998) studied the Eastern Sand Darter in pools of two rivers in West Virginia. Divers could not determine the positions of the sand darters because the fish burrowed into the sandy substrate when approached. Therefore, the locations of sand darters were determined from the shore. The microhabitats of the 10 sand darters observed were characterized by calculating the water velocity and depth, and by determining the substrate size using a grid of 25 cells, each $5 \times 5 \mathrm{~cm}$, centered on the location of the fish. The results showed the mean velocity to be $0 \mathrm{~cm} / \mathrm{sec}$, the mean depth was $32.4( \pm 6.4) \mathrm{cm}$, and the substrate size index was $2.0( \pm 0.4)$, which indicates particles ranging from 0.06 to $2.0 \mathrm{~mm}$. These results are consistent with ours and support our conclusions that the Eastern Sand Darter prefers substrates with small particle size.

Substrate composition is thought to be a factor affecting Eastern Sand Darter habitat utilization because of their characteristic burrowing (Drake et al. 2008), and our aquarium study supports the observations of others (see Grandmaison et al. 2004*) that sand darters tend to burrow. Therefore, changes in substrate composition could impact the fish's ability to use certain areas. Siltation has been thought to be responsible for decreases in Eastern Sand Darter populations throughout their range (Smith 1985; Daniels 1993; Holm and Mandrak 1996). Our results mainly suggested that the Eastern Sand Darter needs fine to medium grain sand and generally does not use areas with high levels of substrate greater than $1.9 \mathrm{~mm}$, although our own field observations indicate that areas with a combination of fine and coarse particles may be acceptable. The Eastern Sand Darter may be unable to burrow easily into 


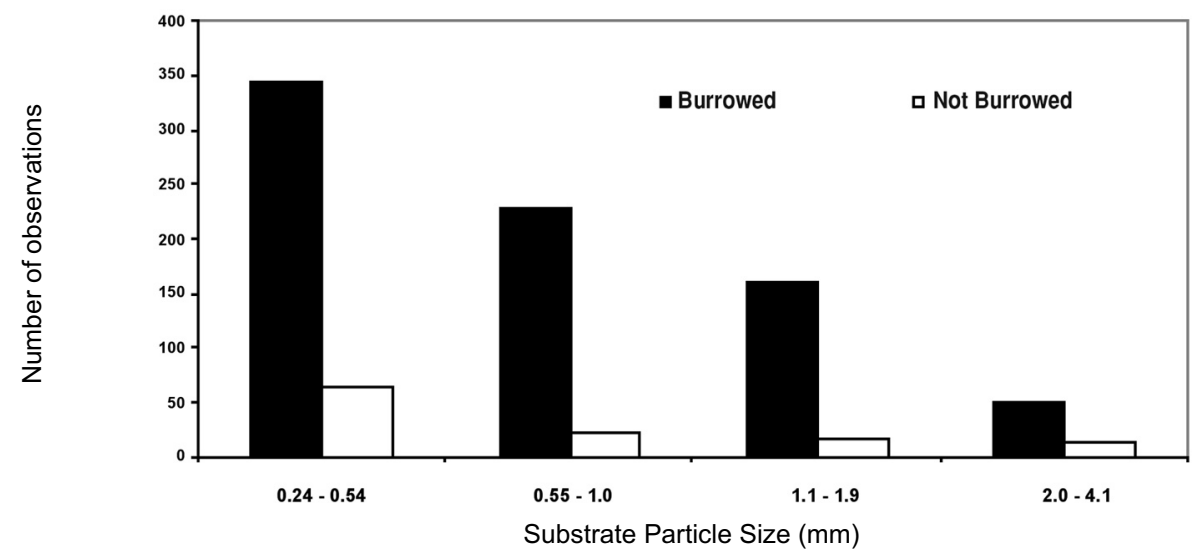

FIGURE 3. The number of times the Eastern Sand Darter was observed either burrowed into or resting on each of the different size sediments during studies in aquaria. The 790 total observations were from multiple observations of 49 different fish.

these coarse substrates, as noted during observations of fish in aquaria. Our results could not assess the impacts of mud or fine silt deposition on habitat use because large amounts of silt and mud were not characteristic of the sections of the rivers that we sampled. However, Drake et al. (2008) showed that age-0 Eastern Sand Darters grew better in areas with more sand than in areas with more silt, and argued that sand-dominated substrates would be energetically beneficial because of higher oxygen levels and greater prey availability.

Some regulations for protecting river water quality, including prevention of excess sediment input, have probably decreased silt loads and improved habitat for the Eastern Sand Darter. For example, Daniels (1993) reported that reforestation of the banks of the Mettawee River (New York) decreased the silt load and may have been responsible for the increase in the availability of sandy habitats for the Eastern Sand Darter. Daniels (1993) also mentioned that Greeley (1930) reported finding no Eastern Sand Darters during a 1929 survey of the Mettawee River and Poultney River (New York-Vermont), and that Greeley's field notes indicated that both rivers had mud bottoms. In contrast, sandy stretches of both of these rivers have supported Eastern Sand Darters since at least the 1980s (Daniels 1989, 1993; Bouton 1991*). The discovery of additional populations in several New York rivers over the last 20 years has resulted in a down-listing of the species from "Endangered" to "Threatened" in New York, and could result in further down-listing to "Special Concern" (Carlson 2008*).

The Eastern Sand Darter is quite selective of substrates utilized. Therefore, changes in substrate composition may impact the ability to utilize an area. This study confirms previous reports that the Eastern Sand Darter uses sandy habitat; however, we also provide a greater degree of resolution by identifying preferred substrate as sand less than $1.1 \mathrm{~mm}$ in size. Previous reports identify habitat alteration by sedimentation as having reduced the habitat suitability for the Eastern Sand Darter throughout much of its range (e.g., Trautman 1957, 1981; Smith 1985; Daniels 1993; Holm and Mandrak 1996, Grandmaison et. al 2004*; COSEWIC $\left.2008^{*}\right)$. Our results suggest that the relative abundance of fine to medium sand ( 0.12 to $1.0 \mathrm{~mm})$ and coarser substrates $(>1.9 \mathrm{~mm}$ ) may also determine the suitability of habitat for, and abundance of, the Eastern Sand Darter.

\section{Acknowledgments}

This project was made possible by financial support from The Nature Conservancy's Freshwater Initiative Small Grants Program, through The Nature Conservancy's Southern Lake Champlain Valley Office. Additional support was provided by the Clare Boothe Luce Foundation, the Lake Champlain Research Consortium, and Saint Michael's College. We also thank Mary Droege of The Nature Conservancy for assistance in the Poultney River, and Leah Staniels, whose preliminary work on habitat use by the Eastern Sand Darter in the Winooski River provided a foundation for us to build upon. We also thank several reviewers for helpful suggestions on the manuscript.

Documents Cited [marked * in text]

Bouton, D. M. 1991. A summary of 1987-91 survey data collected on the Eastern Sand Darter (Ammocrypta pellucida) in the Mettawee River, Poultney River, and Little Salmon - Salmon River systems. Unpublished report of the New York State Department of Environmental Conservation, Division of Fish and Wildlife, Albany, New York. 31 March 1991.

Carlson, D. 2008. Species account: Eastern sand darter (Ammocrypta pellucida). Unpublished report of the New York State Department of Environmental Conservation, Divi- 
sion of Fish and Wildlife, and Marine Resources, Albany, New York. January 2008.

COSEWIC 2008. Canadian Wildlife Species at Risk. Committee on the Status of Endangered Wildlife in Canada. Website:http://www.cosewic.gc.ca/eng/sct0/rpt/rpt_csar_ e.pdf. [accessed 29 March 2009]

Grandmaison, D., J. Mayasich, and D. Etnier. 2004. Eastern Sand Darter Status Assessment. U.S. Fish and Wildlife Service, Region 3. NRRI Technical Report No. NRRI/TR2003/40

\section{Literature Cited}

Clay, W. M. 1975. The fishes of Kentucky. Kentucky Department of Fish and Wildlife Resources, Frankfurt, Kentucky. 416 pages.

Daniels, R. A. 1989. Significance of burying in Ammocrypta pellucida. Copeia 1989: 29-34.

Daniels, R. A. 1993. Habitat of the Eastern Sand Darter, Ammocrypta pellucida. Journal of Freshwater Ecology 8: 287-295.

Drake, D. A. R., M. Power, M. A. Koops, S. E. Doka, and N. E. Mandrak. 2008. Environmental factors affecting growth of eastern sand darter (Ammocrypta pellucida). Canadian Journal of Zoology 86: 714-722.

Facey, D. E. 1998. Status of the Eastern Sand Darter (Ammocrypta pellucida) in Vermont. Canadian Field-Naturalist 112: 596-601.

Facey, D. E., and S. M. O'Brien. 2004. Influence of substrate composition on distribution of Eastern Sand Darters (Ammocrypta pellucida) in the Poultney River. Pages 291-
298 in Lake Champlain: Partnerships and Research in the New Millennium. Edited by T. Manley, P. Manley, and T. Mihuc. Kluwer Press, Boston, Massachusetts. 410 pages. Greeley, J. R. 1930. Fishes of the Lake Champlain watershed. Pages 44-87 in A biological survey of the Champlain watershed. Edited by E. Moore. New York State Department of Conservation, Albany, New York.

Holm, E., and N. E. Mandrak. 1996. The status of the Eastern Sand Darter, Ammocrypta pellucida, in Canada. Canadian Field-Naturalist 110: 462-469.

Page, L. M. 1983. Handbook of darters. TFH Publishers, Inc., Neptune City, New Jersey. 271 pages.

Scott, W. B., and E. J. Crossman. 1973. Freshwater fishes of Canada, Bulletin of the Fisheries Research Board of Canada 184 . xi +966 pages.

Smith, C. L. 1985. The inland fishes of New York State. New York State Department of Environmental Conservation, Albany, New York. 522 pages.

Smith, P. W. 1979. The fishes of Illinois. University of Illinois Press, Urbana, Illinois. 314 pages.

Trautman, M. B. 1957. The fishes of Ohio. Ohio State University Press, Columbus, Ohio. 683 pages.

Trautman, M. B. 1981. The fishes of Ohio. Ohio State University Press, Columbus, Ohio. 782 pages.

Welsh, S. A., and S. A. Perry. 1998. Habitat partitioning in a community of darters in the Elk River, West Virginia. Environmental Biology of Fishes 51: 411-419.

Received 12 June 2008

Accepted 9 April 2009 